\title{
An arachidonic acid-enriched diet does not result in more colonic inflammation as compared with fish oil- or oleic acid-enriched diets in mice with experimental colitis
}

\author{
Julian D. Ramakers ${ }^{1}$, Ronald P. Mensink ${ }^{1}$, Marleen I. Verstege ${ }^{2}$, Anje A. te Velde $^{2}$ and Jogchum Plat ${ }^{1}$ \\ ${ }^{1}$ Department of Human Biology, Nutrition and Toxicology Research Institute Maastricht, Maastricht University, Maastricht, \\ The Netherlands \\ ${ }^{2}$ Department of Experimental Internal Medicine, Academic Medical Centre, University of Amsterdam, Amsterdam, The Netherlands \\ (Received 22 February 2007 - Revised 26 November 2007 - Accepted 27 November 2007 - First published online 21 January 2008)
}

Fish oils (FO) - rich in EPA and DHA - may protect against colitis development. Moreover, inflammatory bowel disease patients have elevated colonic arachidonic acid (AA) proportions. So far, effects of dietary AA $v$. FO on colitis have never been examined. We therefore designed three isoenergetic diets, which were fed to mice for 6 weeks preceding and during $7 \mathrm{~d}$ dextran sodium sulfate colitis induction. The control diet was rich in oleic acid (OA). For the other two diets, $1.0 \%(\mathrm{w} / \mathrm{w})$ OA was exchanged for EPA + DHA (FO group) or AA. At $7 \mathrm{~d}$ after colitis induction, the AA group had gained weight $(0.46$ (SEM 0.54) g), whereas the FO and OA groups had lost weight $(-0.98$ (SEM 0.81) g and -0.79 (SEM 1.05$) \mathrm{g}$, respectively; $P<0.01 v$. AA). The AA group had less diarrhoea than the FO and OA groups $(P<0.05)$. Weight and length of the colon, histological scores and cytokine concentrations in colon homogenates showed no differences. Myeloperoxidase concentrations in plasma and polymorphonuclear cell infiltration in colon were decreased in the FO group as compared with the OA group. We conclude that in this mice model an AAenriched diet increased colonic AA content, but did not result in more colonic inflammation as compared with FO- and OA-enriched diets. As we only examined effects after $7 \mathrm{~d}$ and because the time point for evaluating effects seems to be important, the present results should be regarded as preliminary. Future studies should further elucidate differential effects of fatty acids on colitis development in time.

Dextran sodium sulfate: Colitis: Fish oil: Arachidonic acid: Oleic acid

Epidemiological studies have shown a low incidence of inflammatory bowel disease (IBD) in Eskimos as compared with West-European populations. These findings may be related to their high intakes of $n-3$ fish oil (FO) PUFA, which may have anti-inflammatory effects as compared with in particular $n-6 \mathrm{PUFA}^{(1)}$. Interestingly, other studies have found that the fatty acid composition of phospholipids from the colonic mucosa of IBD patients contained more of the $n-6$ PUFA arachidonic acid (AA) as compared with the colonic mucosa of control subjects ${ }^{(2-4)}$. By increasing the intake of FO, the n-6 PUFA AA in the colon mucosa is replaced by the $n-3$ FO PUFA EPA and DHA ${ }^{(5)}$. Furthermore, in an in vitro study we have recently shown that culturing enterocytes with AA increased inflammatory parameters as compared with enterocytes cultured with EPA or oleic acid $(\mathrm{OA})^{(6)}$. Therefore, it is tempting to suggest that the antiinflammatory effects of $\mathrm{FO}$ are caused by a reduction of the AA content. Alternatively, FO may have their own intrinsic anti-inflammatory effects. Several dietary intervention studies have indeed shown that supplementation of $n-3$ FO have beneficial effects in IBD patients ${ }^{(5,7-16)}$. Although some studies showed rather impressive effects ${ }^{(5,7)}$, it should be noted, however, that not all clinical studies were that positive ${ }^{(8-16)}$. Based on these intervention studies, the overall conclusion was that FO supplementation may have at least minor protective effects ${ }^{(1)}$. Also, in various mouse and rat IBD intervention studies FO has positive effects ${ }^{(17-23)}$, whereas some studies did not find protective effects ${ }^{(24,25)}$. Unfortunately, due to the composition of the diets, these studies could not evaluate specifically the effects of FO $v$. those of AA.

Therefore, the aim of the present study was to examine the in vivo effects of $\mathrm{FO} v$. AA on intestinal inflammation. A diet enriched with the $n-9$ MUFA OA was used as the control diet. The OA of the control diet was isoenergetically exchanged for the $n-3$ PUFA of FO or the $n-6$ PUFA AA. These diets were fed for 6 weeks to female C57BL/6 mice. At the end of this period, dextran sodium sulfate (DSS) colitis was induced for $7 \mathrm{~d}$ and the severity of colonic inflammation and related parameters were evaluated.

Abbreviations: AA, arachidonic acid; DSS, dextran sodium sulfate; En\%, \% energy; FO, fish oil; IBD, inflammatory bowel disease; IFN, interferon; MCP, monocyte chemotactic protein; MPO, myeloperoxidase; OA, oleic acid; SAP, serum amyloid P component.

* Corresponding author: Dr Julian D. Ramakers, fax +3143 3670976, email j.ramakers@hb.unimaas.nl 


\section{Materials and methods}

\section{Animals, diets and experimental design}

Experiments were approved by the Animal Studies Ethics Committee of the University of Amsterdam, The Netherlands. Thirty 4-week-old female wild-type C57BL/6 mice were obtained from Charles River (Horst, The Netherlands). The mice were housed under standard conditions (AM-III $15 \mathrm{~mm}$; Hope Farms, Woerden, The Netherlands) and had free access to water and food. The mice were randomly assigned to three groups of ten mice, which received one of the three diets for 6 weeks before colitis induction. The diets were also fed during the week of DSS colitis induction. All three diets contained the same amounts of protein, carbohydrates and fat providing respectively $21 \%$ energy (En\%), 66 En\% and 14 En\% (Table 1). Of this 14 En\% or $6.0 \%$ (w/w) provided by fat, 8 En\% (or $3.4 \%$, w/w) was part of the standard $(\mathrm{CRM}(\mathrm{E}))$ chow, while $6 \mathrm{En} \%$ (or $2.6 \%$, w/w) was specifically added as enrichment. Thus, the only difference between the diets was the source of $6.0 \mathrm{En} \%$ fat added to the chow. The FO group received normal chow enriched with FO $(2.6 \%$, w/w) (Loders Croklaan, Wormerveer, The Netherlands). Of this $2.6 \%(\mathrm{w} / \mathrm{w}), 1.0 \%(\mathrm{w} / \mathrm{w})$ was EPA plus DHA with a EPA:DHA ratio of 1.4 (Table 1). The AA group received the same chow, but now enriched with arachidonic ethyl ester oil (Nu-Chek-Prep, Elysian, MN, USA) $(1.1 \%, \mathrm{w} / \mathrm{w})$. Of this $1.1 \%(\mathrm{w} / \mathrm{w}), 1.0 \%(\mathrm{w} / \mathrm{w})$ was the arachidonic ethyl ester. In addition, cacao butter $(1.5 \%$, w/w)

Table 1. Composition of the fish oil (FO), arachidonic acid (AA) and oleic acid (OA) diets ( $\mathrm{g} / 100 \mathrm{~g}$ diet unless stated otherwise)

\begin{tabular}{|c|c|c|c|}
\hline Diet... & FO & AA & $\mathrm{OA}$ \\
\hline \multicolumn{4}{|l|}{ Protein } \\
\hline \% Energy & 21 & 21 & 21 \\
\hline $\mathrm{g} / 100 \mathrm{~g}$ diet & 20 & 20 & 20 \\
\hline \multicolumn{4}{|l|}{ Carbohydrates } \\
\hline \% Energy & 66 & 66 & 66 \\
\hline $\mathrm{g} / 100 \mathrm{~g}$ diet & 68 & 68 & 68 \\
\hline \multicolumn{4}{|l|}{ Fat } \\
\hline \% Energy & 14 & 14 & 14 \\
\hline $\mathrm{g} / 100 \mathrm{~g}$ diet & 6 & 6 & 6 \\
\hline $14: 0$ & 0.15 & 0.02 & 0.02 \\
\hline $16: 0$ & 0.91 & 0.97 & 0.93 \\
\hline $18: 0$ & 0.19 & 0.60 & 0.62 \\
\hline $16: 1 n-7$ & 0.13 & 0.02 & 0.02 \\
\hline $18: 1 n-7$ & 0.10 & 0.06 & 0.07 \\
\hline $18: 1 n-9$ & 0.85 & $1 \cdot 15$ & 2.04 \\
\hline $20: 1 n-9$ & 0.07 & 0.04 & 0.05 \\
\hline $18: 2 n-6$ & 1.94 & 1.96 & 1.91 \\
\hline $20: 4 n-6$ & 0.04 & 0.78 & $<0.01$ \\
\hline $18: 3 n-3$ & 0.22 & 0.20 & 0.19 \\
\hline $20: 5 n-3$ & 0.58 & 0.02 & 0.02 \\
\hline $22: 6 n-3$ & 0.41 & 0.05 & 0.04 \\
\hline Others & 0.43 & 0.14 & 0.09 \\
\hline$\sum \mathrm{SFA}^{*}$ & 1.32 & 1.64 & 1.64 \\
\hline$\sum$ MUFA $^{*}$ & $1 \cdot 26$ & $1 \cdot 28$ & $2 \cdot 17$ \\
\hline$\sum \mathrm{PUFA}^{*}$ & 3.42 & 3.08 & $2 \cdot 18$ \\
\hline$\sum n-9^{*}$ & 0.96 & $1 \cdot 20$ & 2.09 \\
\hline$\sum n-6^{*}$ & 2.02 & $2 \cdot 78$ & 1.92 \\
\hline$\sum n-3^{*}$ & 1.39 & 0.29 & 0.26 \\
\hline Ratio $n-6: n-3$ & 1.5 & $9 \cdot 6$ & $7 \cdot 4$ \\
\hline Tocopherol blend & 18 & 18 & 18 \\
\hline
\end{tabular}

${ }^{\star} \sum$ is the sum of all fatty acids belonging to that particular class.
(Special Diet Services, Witham, Essex, UK) was added to the AA diet. In this way, in total $2.6 \%(\mathrm{w} / \mathrm{w})$ fat was added to the chow, which made total fat intake equal to that of the FO diet. The control (OA) group also consumed the normal chow, but now enriched with the same isoenergetic amount $(2.6 \%, \mathrm{w} / \mathrm{w})$ of fatty acids from cacao butter $(1.2 \%, \mathrm{w} / \mathrm{w})$ plus high-oleic sunflower-seed oil $(1.4 \%$, w/w) (Loders Croklaan). All diets were enriched with a tocopherol blend ( $3 \mathrm{mg}$ tocopherols/g fat; Loders Croklaan). All diets were made by Special Diet Services and irradiated at $25 \mathrm{kGy}$. The macronutrient and fatty acid composition of the diets is shown in Table 1. As can be seen, the main difference between the diets is the proportion of OA, which was replaced by $\mathrm{EPA}+\mathrm{DHA}$ or AA. Body weights of the mice were recorded every third day during the first 6 weeks. One mouse of the FO group died in week 4 because of an elephant tooth. After 6 weeks on the experimental diets, colitis was induced in the 10 -week-old mice by administration of $1.5 \%$ (w/v) DSS (molecular weight $40 \mathrm{kDa}$; TdB Consultancy, Uppsala, Sweden) to the drinking water for 1 week. During the week of colitis induction, body weights of the mice were recorded daily. After $7 \mathrm{~d}$ DSS treatment, all mice were anaesthetised with fantanyl-fluanisone-midazolam and killed via a cardiac puncture and exsanguination. Blood was sampled in EDTA tubes (Becton Dickinson Vacutainer Systems, Franklin Lakes, NJ, USA) and plasma was obtained by centrifugation at $2000 \mathrm{~g}$ for $20 \mathrm{~min}$ at $4^{\circ} \mathrm{C}$ and stored at $-80^{\circ} \mathrm{C}$ until analysis for myeloperoxidase (MPO) and serum amyloid P component (SAP) concentrations. Through a midline incision, the colons were removed. First, the total length was measured as an indicator of disease-related colon shortening. In addition, faecal material was removed and collected to score diarrhoea severity; i.e. $0=$ normal faeces; $1=$ loose stool; $2=$ watery diarrhoea; $3=$ slimy diarrhoea, little blood; $4=$ very severe diarrhoea. Next, the colons were opened longitudinally and the wet weight of the distal $6 \mathrm{~cm}$ was recorded and used as an index of disease-related intestinal wall thickening. Subsequently, the colons were divided longitudinally into two parts and both parts were rolled up. These samples were frozen in liquid $\mathrm{N}_{2}$ and stored at $-80^{\circ} \mathrm{C}$ until analysis. For all twenty-nine mice, one roll was used for histological analysis. In five randomly selected mice per group, half of the other roll was used for cytokine detection, while the other half of this roll was used for analysis of intestinal fatty acid composition.

\section{Fatty acid composition of the diets and colon homogenates}

Fatty acid compositions of the diets and colon samples were analysed by GC. Extraction and analysis procedures have been described previously ${ }^{(26)}$. Briefly, total lipids were extracted from about $50 \mathrm{mg}$ diet and $7 \mathrm{mg}$ dried-frozen colon samples according to the method of Bligh \& Dyer ${ }^{(27)}$. Aminopropyl-bonded silica columns (Varian, Harbor City, CA, USA) were used to separate phospholipids from the total lipid extract $^{(28)}$. The phospholipids were then saponified, and the resultant fatty acids were methylated into their corresponding fatty acid methyl esters (FAME) ${ }^{(29)}$. Fatty acids were separated on an Autosystem (Perkin-Elmer, Norwalk, CT, USA) gas chromatograph that was fitted with a silica-gel column (Cp-sil 88 for FAME, $50 \mathrm{~m} \times 0.25 \mathrm{~mm}, 0.2 \mu \mathrm{m}$ film thickness; 
Chrompack, Middelburg, The Netherlands) with $\mathrm{He}$ gas $(130 \mathrm{kPa})$ as the carrier gas. Both the injection and detection temperatures were set at $300^{\circ} \mathrm{C}$. The starting temperature of the column was $160^{\circ} \mathrm{C}$. At $10 \mathrm{~min}$ after injection, the temperature was increased up to $190^{\circ} \mathrm{C}$ at a rate of $2 \cdot 5^{\circ} \mathrm{C} / \mathrm{min}$. After $20 \mathrm{~min}$ at $190^{\circ} \mathrm{C}$, the temperature was increased up to $230^{\circ} \mathrm{C}$ at a rate of $4^{\circ} \mathrm{C} / \mathrm{min}$. The final temperature of $230^{\circ} \mathrm{C}$ was maintained for $10 \mathrm{~min}$. Data were analysed by using CHROMCARD software (version 1.21; CE Instruments, Milan, Italy). The fatty acid compositions are expressed in relative amounts (\% of total fatty acids identified; w/w).

\section{Histological analysis}

The longitudinally divided rolled-up parts of the colon, which were used for routine histology, were directly fixed in $4 \%$ formaldehyde and embedded in paraffin. Three transverse slices $(5 \mu \mathrm{m})$, taken from each colonic sample, were stained with haematoxylin-eosin, and examined by light microscopy. Colonic inflammation was evaluated in a blind manner by estimating: (1) percentage of area involved; (2) the amount of follicles (these are lymphoid aggregates characteristic for intestinal tissue); (3) oedema; (4) erosion/ulceration; (5) crypt loss; (6) infiltration of polymorphonuclear cells; (7) infiltration of mononuclear cells. The percentage of area involved, erosion/ulceration and the crypt loss was scored on a scale ranging from 0 to 4 as follows: $0=$ normal; $1=<10 \%$; $2=10-25 \% ; 3=25-50 \% ; 4=>50 \%$. Follicle aggregates were counted and scored as follows: $0=$ zero to one follicle; $1=$ two to three follicles; $2=$ four to five follicles; $3=$ six follicles or more. The severity of the other parameters was scored on a scale from 0 to 3 as follows: $0=$ absent; $1=$ weak; $2=$ moderate; $3=$ severe. All scores on the individual parameters together could result in a total score ranging from 0 to 24 .

\section{Homogenisation and cytometric bead array}

For analysis of cytokine concentrations, homogenates were made from colon samples with a tissue homogeniser in 9 volumes (w/v) Greenberger lysis buffer $(300 \mathrm{~mm}-\mathrm{NaCl}$, 15 mM-2-amino-2-hydroxymethyl-1,3-propanediol, $2 \mathrm{mM}$ $\mathrm{MgCl}_{2}, 2$ mM-Triton X-100 (Sigma, St Louis, MO, USA), pepstatin A, leupeptin, aprotinine (Roche, Mannheim, Germany), all $20 \mathrm{ng} / \mathrm{ml} ; \mathrm{pH} 7 \cdot 4)$. The colon homogenates were lysed in the Greenberger lysis buffer for $1 \mathrm{~h}$ on ice and centrifuged for $7 \mathrm{~min}$ at $3000 \mathrm{rpm}$ and for $10 \mathrm{~min}$ at $14000 \mathrm{rpm}$. The supernatant fraction was collected and stored at $-80^{\circ} \mathrm{C}$ until cytokine analysis using a cytometric bead array. The mouse inflammation and Th1/Th2 cytometric bead arrays (Becton Dickinson Biosciences, San Diego, CA, USA) were used in colon homogenates to determine simultaneously the concentrations of IL-2, IL-4, IL-6, IL-10, IL-12p70, monocyte chemotactic protein (MCP)-1, interferon (IFN) $\gamma$ and $\mathrm{TNF} \alpha$ according to the instructions of the manufacturer. Briefly, $5 \mu l$ of sample or the cytokine standard mixture was mixed with $5 \mu \mathrm{l}$ mixed capture beads and $5 \mu \mathrm{l}$ detection antibodyphycoerethrine reagent and incubated at room temperature for $2 \mathrm{~h}$ in the dark. Two-colour flow cytometric analysis was performed using a FACScan ${ }^{\circledR}$ flow cytometer (Becton Dickinson Immunocytometry Systems, San Jose, CA, USA).
Data were acquired and analysed using Becton Dickinson Cytometric Bead Array software.

\section{Myeloperoxidase in colon homogenates and plasma}

To quantify the extent of colonic neutrophil accumulation and systemic neutrophil amounts, MPO concentrations in colon homogenates and EDTA plasma were analysed by ELISA (HBT, Uden, The Netherlands). All samples of all groups were analysed on one plate. The detection limit of the MPO ELISA was $1.02 \mathrm{ng} / \mathrm{ml}$. The intra-assay variation was less than $7.5 \%$.

\section{Serum amyloid $P$ component in plasma}

To evaluate the acute-phase reaction activity, SAP concentrations were analysed in EDTA plasma by ELISA, as described $^{(30)}$. Briefly, a ninety-six-well plate (Greiner BioOne; Frickenhausen, Germany) was coated with $3 \mu \mathrm{g} / \mathrm{ml}$ sheep-antimouse SAP (Calbiochem, San Diego, CA, USA) antibodies. Immobilised SAP was detected using a specific biotinylated rabbit-antimouse SAP antibody (Calbiochem), followed by the addition of peroxidase-conjugated streptavidin (Zymed Laboratories, San Francisco, CA, USA) and tetramethylbenzidine substrate (Kirkegaard and Perry Laboratories, Gaithersburg, MD, USA). All samples of all groups were analysed on one plate. The detection limit of the SAP ELISA was $5 \mathrm{ng} / \mathrm{ml}$. The intra-assay variation was less than $5 \%$.

\section{Statistics}

All data, except body weights (mean values with their standard errors), are expressed as dot plots in which the median is indicated. Differences between the three groups (AA $v$. FO $v$. OA) were analysed using the Kruskall-Wallis test. If a significant difference was found $(P<0.05)$ the Mann-Whitney $U$ test was used as a post hoc test. If the Mann-Whitney post hoc test was performed, a $P<0.017$ was considered as statistically significant. Weight changes in time were tested by one-way ANOVA $(P<0.05)$ with a Bonferonni post hoc test when differences between interventions were significantly different. Correlation analyses were performed using the Spearman correlation test. Values of $P<0.05$ were considered statistically significant. SPSS 10 for Macintosh (SPSS, Inc., Chicago, IL, USA) was used for the analysis.

\section{Results}

\section{Fatty acid composition of the diets and colon homogenates}

Table 1 shows that the fatty acid compositions of the three diets were as anticipated. The OA diet contained more MUFA and less PUFA than the other two diets. Further, the total amounts of MUFA and PUFA were not different between the AA and FO diets. However, the AA diet provided more of the $n-6$ PUFA AA, while the FO diet contained more of the $n-3$ PUFA EPA and DHA. This resulted in a higher $n-6: n-3$ ratio in the AA diet than in the FO diet. The only other difference was a slightly lower SFA content in the FO diet as compared with the $\mathrm{OA}$ and $\mathrm{AA}$ diets. 
Table 2 shows that differences in fatty acid composition of the colons between groups paralleled those of the diets. In the AA group, the proportions of $n-6$ PUFA (20:4 and longer) were increased, whereas the proportion of $18: 2 n-6$ was decreased compared with the OA and FO groups. Moreover, the $n$-3 PUFA in the AA group were decreased, which resulted in an increased $n-6: n-3$ ratio compared with the OA and FO groups. In the FO group, the proportions of $n-3$ PUFA were increased, while those of $n-6$ PUFA were decreased compared with the OA and AA groups. This resulted in a decreased $n-6: n-3$ ratio as compared with the OA and AA groups.

\section{Body weight before and after dextran sodium sulfate colitis} induction

During the 6 weeks preceding colitis induction, weight changes were not significantly different between the three groups $(P=0 \cdot 290)$ Fig. 1 (a).

After $7 \mathrm{~d}$ DSS treatment, both the FO- and the OA-fed mice had lost weight $(-0.98$ (SEM 0.81$) \mathrm{g}$, or $-4 \%$ of their initial weight at DSS induction, for the FO group and -0.79 (SEM 1.05 ) g, or $-4 \%$, for the OA group) (Fig. 1 (b)). In contrast, weight of the AA-fed mice first decreased until day 5, but was slightly increased after $7 \mathrm{~d}(0.46$ (SEM 0.54$) \mathrm{g}$, or $2 \%$ of their initial weight at DSS induction). At day 5 the AA-fed mice had lost significantly more weight than the FO- and OA-fed mice $(P<0.001)$, but at day 7 the AA group had gained significantly more weight than the FO $(P=0.002)$ and control groups $(P=0 \cdot 007)$

Table 2. Fatty acid composition of phospholipids in the colon from dextran sodium sulfate colitis mice fed a fish oil (FO) diet, arachidonic acid (AA) diet and oleic acid (OA) diet (\% of total fatty acids)

(Mean values and standard deviations of five mice per diet group)

\begin{tabular}{|c|c|c|c|c|c|c|}
\hline \multirow{2}{*}{$\begin{array}{l}\text { Diet... } \\
\text { Fatty acid }\end{array}$} & \multicolumn{2}{|c|}{ FO } & \multicolumn{2}{|c|}{ AA } & \multicolumn{2}{|c|}{ OA } \\
\hline & Mean & SD & Mean & SD & Mean & SD \\
\hline $16: 0$ & $22 \cdot 3^{b}$ & 0.2 & $21 \cdot 7^{\mathrm{a}, \mathrm{b}}$ & 0.6 & $20 \cdot 5^{a}$ & 1.5 \\
\hline $18: 0$ & $15 \cdot 2^{a}$ & 0.1 & $15 \cdot 8^{a}$ & 0.8 & $15 \cdot 7^{\mathrm{a}}$ & 1.0 \\
\hline $22: 0$ & $1 \cdot 1^{\mathrm{a}}$ & 0.1 & $1 \cdot 1^{\mathrm{a}}$ & 0.1 & $1 \cdot 0^{a}$ & 0.1 \\
\hline $24: 0$ & $1 \cdot 2^{\mathrm{b}}$ & 0.2 & $1 \cdot 0^{\mathrm{a}, \mathrm{b}}$ & 0.1 & $0.9^{a}$ & 0.0 \\
\hline $16: 1 n-7$ & $1 \cdot 3^{a}$ & 0.2 & $1 \cdot 1^{a}$ & 0.4 & $1.0^{\mathrm{a}}$ & 0.4 \\
\hline $18: 1 n-7$ & $2 \cdot 3^{a}$ & 0.1 & $2 \cdot 4^{a}$ & 0.5 & $2 \cdot 4^{a}$ & 0.4 \\
\hline $18: 1 n-9$ & $10 \cdot 7^{c}$ & 0.7 & $9 \cdot 1^{\mathrm{b}}$ & 0.6 & $12 \cdot 8^{a}$ & 0.7 \\
\hline $24: 1 n-9$ & $1 \cdot 6^{a}$ & 0.3 & $1.4^{\mathrm{a}}$ & 0.2 & $1 \cdot 8^{a}$ & 0.2 \\
\hline $18: 2 n-6$ & $10 \cdot 5^{c}$ & 0.8 & $4 \cdot 3^{b}$ & 1.0 & $8 \cdot 8^{a}$ & 0.6 \\
\hline $20: 3 n-6$ & $2 \cdot 3^{a, b}$ & 0.3 & $1.9^{a}$ & 0.3 & $2 \cdot 8^{b}$ & 0.4 \\
\hline $20: 4 n-6$ & $8 \cdot 9^{c}$ & 0.2 & $23 \cdot 6^{b}$ & 0.6 & $15 \cdot 8^{a}$ & 1.4 \\
\hline $22: 4 n-6$ & $0.7^{c}$ & 0.1 & $4 \cdot 1^{b}$ & 0.3 & $2 \cdot 4^{\mathrm{a}}$ & 0.3 \\
\hline $22: 5 n-6$ & $0.2^{c}$ & 0.0 & $1.0^{\mathrm{b}}$ & 0.1 & $0.4^{a}$ & 0.0 \\
\hline $20: 5 n-3$ & $4 \cdot 4^{\mathrm{b}}$ & 0.6 & $0.3^{a}$ & 0.1 & $0.6^{a}$ & 0.2 \\
\hline $22: 5 n-3$ & $2 \cdot 8^{\mathrm{C}}$ & 0.4 & $0.7^{\mathrm{b}}$ & 0.1 & 0.9 & 0.1 \\
\hline $22: 6 n-3$ & $9 \cdot 8^{\mathrm{c}}$ & 0.6 & $5 \cdot 4^{\mathrm{b}}$ & 0.3 & $7 \cdot 1^{a}$ & 0.6 \\
\hline Others & $5 \cdot 0^{a}$ & 0.2 & $5 \cdot 3^{a}$ & 0.4 & $5 \cdot 1^{a}$ & 0.6 \\
\hline$\sum \mathrm{SFA}^{*}$ & $41.9^{a}$ & 0.4 & $41 \cdot 7^{a}$ & 0.6 & $40 \cdot 0^{b}$ & 1.0 \\
\hline$\sum$ MUFA $^{*}$ & $16 \cdot 9^{a}$ & 0.5 & $15 \cdot 4^{a}$ & $1 \cdot 1$ & $19 \cdot 3^{b}$ & 1.3 \\
\hline$\sum$ PUFA* & $41 \cdot 1^{a}$ & 0.6 & $42.9^{a}$ & 0.7 & $40 \cdot 7^{a}$ & 1.6 \\
\hline$\sum n-9^{*}$ & $12 \cdot 8^{\mathrm{C}}$ & 0.6 & $11 \cdot 3^{b}$ & 0.5 & $15 \cdot 5^{a}$ & 0.6 \\
\hline$\sum n-6^{*}$ & $23 \cdot 8^{c}$ & 0.8 & $35.9^{b}$ & 0.9 & $31 \cdot 5^{\mathrm{a}}$ & $1 \cdot 7$ \\
\hline$\sum n-3^{*}$ & $17 \cdot 1^{c}$ & 0.4 & $6 \cdot 6^{b}$ & 0.3 & $9 \cdot 0^{\mathrm{a}}$ & 0.5 \\
\hline Ratio $n-6: n-3$ & $1 \cdot 4^{c}$ & 0.1 & $5 \cdot 4^{\mathrm{b}}$ & 0.4 & $3.5^{\mathrm{a}}$ & 0.3 \\
\hline
\end{tabular}

a,b,c Mean values within a row with unlike superscript letters were significantly different $(P<0.17$; post hoc Mann-Whitney test with Bonferroni correction). ${ }^{*} \sum$ is the sum of all fatty acids belonging to that particular class.

\section{Diarrhoea}

At $7 \mathrm{~d}$ after the induction of DSS colitis, diarrhoea of the mice was scored (Fig. 1 (c)). In agreement with the increase in body weight of the AA-fed mice, these mice had less diarrhoea (median score 1.5) than the FO (score 3.0;P=0.002) and OA (score 2.5, $P=0.029$ ) fed mice. Body-weight changes correlated negatively with diarrhoea score $(r-0.574 ; P=0.001)$, indicating that a higher diarrhoea score was associated with more body-weight loss.

\section{Length and weight of the colon}

After killing the mice, the total length and the weight of the last $6 \mathrm{~cm}$ of the colon were determined and used as indicators of disease-related colon shortening and intestinal wallthickening respectively. Although body-weight changes correlated with colon length $(r 0.461 ; P=0.012)$, colonic lengths of the mice were, however, not significantly different between the groups $(P=0.497$; Fig. 1 (d)). Colonic weights were also comparable $(P=0 \cdot 138$; Fig. $1(\mathrm{e}))$. As a reference, the approximate colonic weight and length of non-diseased C57BL/6 mice on a standard chow diet are about $140 \mathrm{mg}$ and $7.5 \mathrm{~cm}$, respectively.

\section{Histology}

Colonic inflammation was also evaluated by histological analysis. Irrespective of the diet consumed, all mice showed common pathological features of mild to moderate colitis as crypt loss, ulceration of the mucosa, oedema, and granulocyte and mononuclear cell infiltration in the mucosa. There were no significant differences in total colitis scores between the three diet groups (FO score median 11.5 (range 8.0-16.0), AA score 13.0 (range 3.5-14.5), OA score 12.3 (range 8.0-16.0); $P=0.854)$. Also when the scores of the individual parameters (area involved, follicle aggregates, oedema, ulceration, crypt loss, polymorphonuclear cells and mononuclear cells) were examined, no significant differences between the groups could be found (data not shown). The most interesting difference was the polymorphonuclear cell infiltration (median score 1.0 (range $0 \cdot 0-2 \cdot 0)$ ) in the FO group, which tended to be lower $(P=0.047)$ as compared with the OA group (score 1.75 (range 0.5-2.5)), whereas the differences between the other groups were not significantly different.

Cytokines, myeloperoxidase and serum amyloid $P$ component concentrations in colon homogenates and/or plasma

The concentrations of eight different cytokines in colon homogenates were analysed by a cytometric bead array to evaluate the extent and characteristics of the local colonic inflammation. However, the colonic concentrations of IL-12p70, TNF $\alpha$, IFN $\gamma$, MCP-1, IL-10, IL-6, IL-4 and IL-2 were not significantly different between the three groups. For example, median concentrations (in $\mathrm{ng} / \mathrm{g}$ colonic wet weight) for $\mathrm{TNF} \alpha$ were respectively 0.48 (range $0.28-0.85$ ), 0.49 (range $0.23-1.45$ ) and 0.76 (range $0.37-2.06$ ) for the FO, AA and OA groups.

To determine colonic neutrophil accumulation and systemic neutrophil levels, MPO concentrations were analysed in colon 


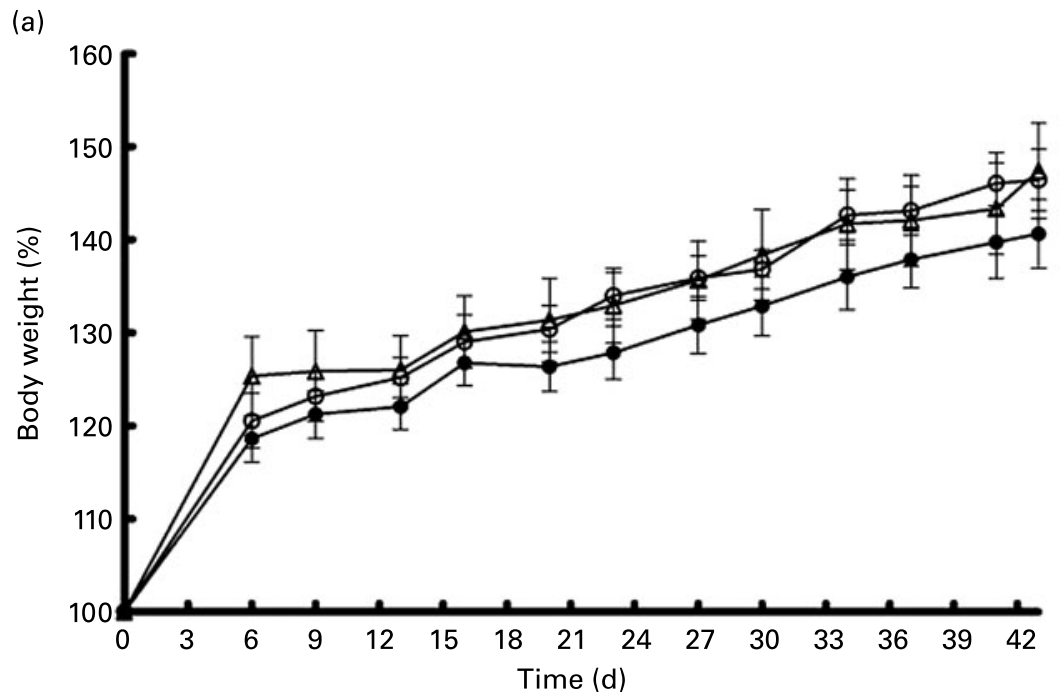

(b)

(c)
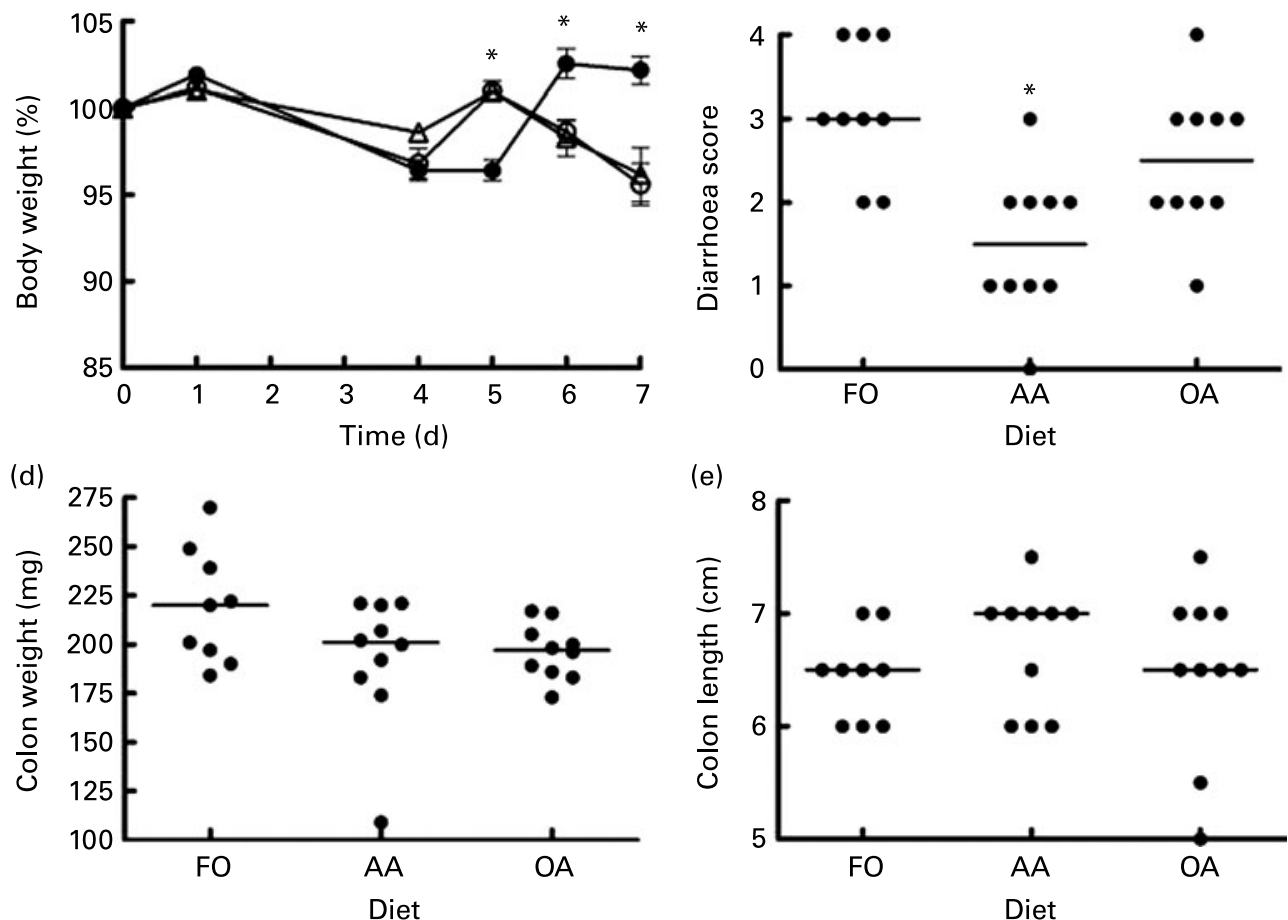

Fig. 1. Effects of a fish oil (FO; - - -), arachidonic acid (AA; - - $)$ ) and oleic acid $(\mathrm{OA} ;-\triangle-)$ diet on dextran sodium sulfate (DSS) colitis disease severity. Ten female mice consumed an FO-enriched diet, an AA-enriched diet or an OA-enriched diet for $43 \mathrm{~d}$ before DSS colitis induction. Colitis was induced by $1.5 \%$ (w/v) DSS in the drinking water for $7 \mathrm{~d}$. Body weight was recorded before colitis induction (a) and after colitis induction as a measure of disease activity (b). Values are means, with their standard errors represented by vertical bars. Furthermore, disease severity was measured at $7 \mathrm{~d}$ after DSS colitis induction by a diarrhoea score (c), weight of the last $6 \mathrm{~cm}$ of the colon (d) and colon length (e). Medians are represented by horizontal bars. ${ }^{\star} P<0.05$.

homogenates and in plasma. Although differences in plasma MPO concentration were small, the MPO concentration (in $\mathrm{ng} / \mathrm{ml}$ ) was significantly lower in the $\mathrm{FO}$ group (median 3.3 (range 3.0-6.5)) compared with the OA group (4.8 (range 3.4-14.2) $\quad(P=0.010)$, but not $v$. the AA group (4.1 (range 3.0-23.3)). However, in colon homogenates no significant differences in MPO concentrations (in $\mathrm{mg} / \mathrm{g}$ colonic wet weight) between the three groups (respectively, FO 0.48 (range 0.21-1.52); AA 0.84 (range 0.14-1.26); OA 0.50 (range $0 \cdot 26-1 \cdot 16$ ) were found. MPO concentrations in colon homogenates correlated with IL-12p70 ( $r$ 0.546; $P=0.035), \mathrm{IFN} \gamma(r$ 0.712; $P=0.003)$ and MCP-1 $(r$ 0.743; $P=0.002)$ concentrations in these homogenates.

To determine the extent of the acute-phase response, we analysed plasma SAP concentrations. SAP concentrations (in $\mathrm{ng} / \mathrm{ml}$ ) did not differ between the three groups (respectively, FO median 64 (range 30-126); AA 44 (range 10-129); OA 87 (range $21-884) ; P=0 \cdot 121$ ). SAP concentrations correlated with $\mathrm{TNF} \alpha(r 0.611 ; P=0.016)$ and IFN $\gamma$ ( $r 0.522 ; P=0.046)$ concentrations in colon homogenates. 


\section{Discussion}

In the present study we show that 6 weeks' consumption of an AA-enriched diet $v$. an FO- or OA-enriched diet preceding and during DSS colitis induction in mice did not result in more pronounced colonic inflammation after $7 \mathrm{~d}$ of colitis induction. In fact, after $7 \mathrm{~d}$, weight loss and diarrhoea score were less in the AA group as compared with the FO and OA groups. Thus, increasing AA intake was not harmful, but may even have been protective in this DSS-induced colitis model, at least $7 \mathrm{~d}$ after colitis induction. However, at $5 \mathrm{~d}$ after colitis induction, weight loss in the AA group was significantly larger than in the FO and OA groups. Also calculating a disease activity index of the weight loss and diarrhoea severity as described previously by Cooper et al. ${ }^{(31)}$ led to the same conclusions. Thus the time point of evaluating the effects of the diets seems essential and in future studies different time points should be evaluated. The present results should therefore be regarded as preliminary. Although some parameters showed protective effects of AA supplementation, all other inflammatory parameters, i.e. colon weight and length, histological scores, and cytokine concentrations in colon homogenates, showed no differences between the groups at $7 \mathrm{~d}$ after DSS colitis induction. Also no protective effects of FO as compared with OA were shown. Only MPO concentrations in plasma and polymorphonuclear cell infiltration in the colon were slightly decreased in the FO group as compared with the OA group. This could suggest that the protective effects of FO had just started and FO might have protective effects at later time points (i.e. $>7 \mathrm{~d}$ ), for example, in the resolution phase of colitis. This has also been suggested by the production of resolvins and protectins, generated from FO fatty acids during the resolution phase of inflammation ${ }^{(32)}$. In contrast, the effects of AA seem most pronounced in the early stage (day 7), for example, in the induction phase. Thus comparing effects of AA $v$. FO both at earlier and later time points after colitis induction should be evaluated in future studies.

In various mouse and rat IBD intervention studies FO had positive effects ${ }^{(17-23)}$, whereas in some studies it did not $^{(24,25,33)}$. Various differences between the models or designs may have contributed to these differences. In some studies showing protective effects on colitis development, effects of FO were compared with those of the $n-6$ fatty acid linoleic acid $(18: 2 n-6)$, while in the present study a comparison between FO and AA was made. Although dietary linoleic acid can be converted into AA, the only two colitis dietary intervention studies that measured colonic fatty acid composition showed no differences in colonic contents of AA between the linoleic acid-rich and FO-rich diets ${ }^{(17,18)}$. In line with our findings, other studies showed that increasing dietary AA resulted in pronounced increases in tissue AA contents ${ }^{(34-36)}$ and that $n-3$ PUFA supplementation reduced tissue AA contents ${ }^{(34,37,38)}$. These findings support our approach of using dietary AA itself instead of $n-6$ precursor PUFA to compare effects of AA and FO on colitis development. To summarise, the two studies that used a linoleic acid-rich control diet and showed no differences in colonic contents of AA showed protective effects of $\mathrm{FO}^{(17,18)}$. In line with the present results, Camuesco et al. ${ }^{(18)}$ did not show a protective effect of FO $v$. an OA-rich diet. Whether the differences in effect on colonic fatty acid composition can explain the possible differences between FO studies remains to be determined. However, also several other differences in the methodology of these two studies compared with the present study could explain the differences in outcome. In the present study, colitis was induced in mice by DSS, whereas Nieto et al. ${ }^{(17)}$ induced experimental colitis in rats by 2,4,6-trinitrobenzenesulfonic acid. Furthermore, they supplied the different diets after colitis induction (therapeutic approach), whereas we supplied the different diets for a period of 6 weeks preceding colitis induction (preventive approach). Camuesco et al. ${ }^{(18)}$ started - in line with our approach experimental diets before DSS colitis induction in rats, but only for 2 weeks instead of 6 weeks. Thus, it is also possible that results depend on the time of supplementation or the type of model used. Indeed, inconsistent effects of FO $v$. control diets have been shown in different mice models. Protective effects in a CD45RB ${ }^{\text {hi }}$ T-cell transfer model ${ }^{(22)}$, no effects in DSS-colitis models ${ }^{(24,33)}$, or even increased colitis in an IL-10 knockout chronic colitis model ${ }^{(25)}$ have been reported for FO. Finally, our DSS mouse model is sensitive to dietary manipulation since protective effects of conjugated linoleic acid and antioxidants such as rutin and glutathione have been shown ${ }^{(39-42)}$.

In the present study, AA was supplied as ethyl ester while OA, and EPA and DHA were supplied as TAG. Although ethyl esters may be less efficiently absorbed in the intestine as compared with $\mathrm{TAG}^{(43-45)}$, the fatty acid composition of the colon clearly represented the fatty acid composition of the diets, which suggests appropriate intestinal AA absorption. Moreover, many FO capsules that have been successfully used in human studies (for example, in the GISSI-trial; Gruppo Italiano per lo Studio della Sopravvivenza nell'Infarto Miocardico, an Italian group for the study of survival of myocardial infarction) contained EPA and DHA as ethyl esters ${ }^{(46)}$. Therefore, AA being supplied as ethyl esters is not an explanation for the results observed.

In conclusion, we here present data that an AA-enriched diet consumed 6 weeks preceding colitis induction increased colonic AA content, but did not result in more colonic inflammation. The AA-enriched diet may even have been protective in a DSS-induced colitis model, as shown by a decreased weight loss and lower diarrhoea scores as compared with FO- or OAenriched diets, $7 \mathrm{~d}$ after colitis induction. Since we only examined effects after $7 \mathrm{~d}$ and because the time point for evaluating effects seems important, these results should be confirmed or refuted by studies using earlier and later time points.

\section{Acknowledgements}

We thank Loders Croklaan for providing the fish and higholeic sunflower-seed oils and tocopherol mixture. We thank Joost Daalhuisen for his excellent biotechnical assistance and Professor Dr Fiebo J. ten Kate for microscopic scoring of the paraffin sections. We thank Hasibe Aydeniz for the determination of the fatty acid composition and Joep Derikx and Mohammed Hadfoune for assistance with MPO and SAP measurements.

J. R. conducted the dietary intervention study and analysis. M. V. contributed to the study and analysis. R. M., A. V. and J. P. designed and supervised the study. All authors contributed 
to the writing of the paper. None of the authors had any conflicts of interest.

\section{References}

1. Belluzzi A (2002) $n$-3 Fatty acids for the treatment of inflammatory bowel diseases. Proc Nutr Soc 61, 391-395.

2. Nishida T, Miwa H, Shigematsu A, Yamamoto M, Iida M \& Fujishima M (1987) Increased arachidonic acid composition of phospholipids in colonic mucosa from patients with active ulcerative colitis. Gut 28, 1002-1007.

3. Buhner S, Nagel E, Korber J, Vogelsang H, Linn T \& Pichlmayr $R$ (1994) Ileal and colonic fatty acid profiles in patients with active Crohn's disease. Gut 35, 1424-1428.

4. Pacheco S, Hillier K \& Smith C (1987) Increased arachidonic acid levels in phospholipids of human colonic mucosa in inflammatory bowel disease. Clin Sci (Lond) 73, 361-364.

5. Hawthorne AB, Daneshmend TK, Hawkey CJ, Belluzzi A, Everitt SJ, Holmes GK, Malkinson C, Shaheen MZ \& Willars JE (1992) Treatment of ulcerative colitis with fish oil supplementation: a prospective 12 month randomised controlled trial. Gut 33, 922-928.

6. Ramakers JD, Mensink RP, Schaart G \& Plat J (2007) Arachidonic acid but not eicosapertaenoic acid (EPA) and oleic acid activates NF-kappaB and elevates ICAM-1 expression in Caco-2 cells. Lipids 42, 687-698.

7. Belluzzi A, Brignola C, Campieri M, Pera A, Boschi S \& Miglioli M (1996) Effect of an enteric-coated fish-oil preparation on relapses in Crohn's disease. N Engl J Med 334, 1557-1560.

8. Stenson WF, Cort D, Rodgers J, Burakoff R, DeSchryver-Kecskemeti K, Gramlich TL \& Beeken W (1992) Dietary supplementation with fish oil in ulcerative colitis. Ann Intern Med 116, 609-614.

9. Almallah YZ, El-Tahir A, Heys SD, Richardson S \& Eremin O (2000) Distal procto-colitis and $n-3$ polyunsaturated fatty acids: the mechanism(s) of natural cytotoxicity inhibition. Eur J Clin Invest 30, 58-65.

10. Salomon P, Kornbluth AA \& Janowitz HD (1990) Treatment of ulcerative colitis with fish oil $n$-3-omega-fatty acid: an open trial. J Clin Gastroenterol 12, 157-161.

11. McCall TB, O'Leary D, Bloomfield J \& O'Morain CA (1989) Therapeutic potential of fish oil in the treatment of ulcerative colitis. Aliment Pharmacol Ther 3, 415-424.

12. Lorenz-Meyer H, Bauer P, Nicolay C, Schulz B, Purmann J, Fleig WE, Scheurlen C, Koop I, Pudel V \& Carr L (1996) Omega-3 fatty acids and low carbohydrate diet for maintenance of remission in Crohn's disease. A randomized controlled multicenter trial. Study Group Members (German Crohn's Disease Study Group). Scand J Gastroenterol 31, 778-785.

13. Loeschke K, Ueberschaer B, Pietsch A, Gruber E, Ewe K, Wiebecke B, Heldwein W \& Lorenz R (1996) $n$-3 Fatty acids only delay early relapse of ulcerative colitis in remission. Dig Dis Sci 41, 2087-2094.

14. Lorenz R, Weber PC, Szimnau P, Heldwein W, Strasser T \& Loeschke K (1989) Supplementation with $n$-3 fatty acids from fish oil in chronic inflammatory bowel disease - a randomized, placebo-controlled, double-blind cross-over trial. J Intern Med Suppl 731, 225-232.

15. Dichi I, Frenhane P, Dichi JB, Correa CR, Angeleli AY, Bicudo MH, Rodrigues MA, Victoria CR \& Burini RC (2000) Comparison of omega-3 fatty acids and sulfasalazine in ulcerative colitis. Nutrition 16, 87-90.

16. Aslan A \& Triadafilopoulos G (1992) Fish oil fatty acid supplementation in active ulcerative colitis: a double-blind, placebo-controlled, crossover study. Am J Gastroenterol 87, $432-437$.
17. Nieto N, Torres MI, Rios A \& Gil A (2002) Dietary polyunsaturated fatty acids improve histological and biochemical alterations in rats with experimental ulcerative colitis. J Nutr 132, $11-19$.

18. Camuesco D, Galvez J, Nieto A, Comalada M, Rodriguez-Cabezas ME, Concha A, Xaus J \& Zarzuelo A (2005) Dietary olive oil supplemented with fish oil, rich in EPA and DHA (n-3) polyunsaturated fatty acids, attenuates colonic inflammation in rats with DSS-induced colitis. J Nutr 135, 687-694.

19. Empey LR, Jewell LD, Garg ML, Thomson AB, Clandinin MT \& Fedorak RN (1991) Fish oil-enriched diet is mucosal protective against acetic acid-induced colitis in rats. Can J Physiol Pharmacol 69, 480-487.

20. Yuceyar H, Ozutemiz O, Huseyinov A, Saruc M, Alkanat M, Bor S, Coker I \& Batur Y (1999) Is administration of $n-3$ fatty acids by mucosal enema protective against trinitrobenzene-induced colitis in rats? Prostaglandins Leukot Essent Fatty Acids 61, 339-345.

21. Guarner F, Vilaseca J \& Malagelada JR (1992) Dietary manipulation in experimental inflammatory bowel disease. Agents Actions Special Conference Issue, C10-C14.

22. Whiting CV, Bland PW \& Tarlton JF (2005) Dietary $n-3$ polyunsaturated fatty acids reduce disease and colonic proinflammatory cytokines in a mouse model of colitis. Inflamm Bowel Dis 11, 340-349.

23. Vilaseca J, Salas A, Guarner F, Rodriguez R, Martinez M \& Malagelada JR (1990) Dietary fish oil reduces progression of chronic inflammatory lesions in a rat model of granulomatous colitis. Gut 31, 539-544.

24. Tenikoff D, Murphy KJ, Le M, Howe PR \& Howarth GS (2005) Lyprinol (stabilised lipid extract of New Zealand green-lipped mussel): a potential preventative treatment modality for inflammatory bowel disease. J Gastroenterol 40, 361-365.

25. Hegazi RA, Saad RS, Mady H, Matarese LE, O'Keefe S \& Kandil HM (2006) Dietary fatty acids modulate chronic colitis, colitis-associated colon neoplasia and COX-2 expression in IL-10 knockout mice. Nutrition 22, 275-282.

26. Wensing AG, Mensink RP \& Hornstra G (1999) Effects of dietary $n-3$ polyunsaturated fatty acids from plant and marine origin on platelet aggregation in healthy elderly subjects. Br J Nutr $\mathbf{8 2}$, 183-191.

27. Bligh EG \& Dyer WJ (1959) A rapid method of total lipid extraction and purification. Can J Biochem Physiol 37, 911-917.

28. Kaluzny MA, Duncan LA, Merritt MV \& Epps DE (1985) Rapid separation of lipid classes in high yield and purity using bonded phase columns. J Lipid Res 26, 135-140.

29. Morrison WR \& Smith LM (1964) Preparation of fatty acid methyl esters and dimethylacetals from lipids with boron fluoride-methanol. J Lipid Res 5, 600-608.

30. Daemen MA, Heemskerk VH, van't Veer C, Denecker G, Wolfs TG, Vandenabeele P \& Buurman WA (2000) Functional protection by acute phase proteins $\alpha(1)$-acid glycoprotein and $\alpha(1)$-antitrypsin against ischemia/reperfusion injury by preventing apoptosis and inflammation. Circulation 102 , $1420-1426$.

31. Cooper HS, Murthy SN, Shah RS \& Sedergran DJ (1993) Clinicopathologic study of dextran sulfate sodium experimental murine colitis. Lab Invest 69, 238-249.

32. Serhan CN (2005) Novel eicosanoid and docosanoid mediators: resolvins, docosatrienes, and neuroprotectins. Curr Opin Clin Nutr Metab Care 8, 115-121.

33. Bassaganya-Riera J, Reynolds K, Martino-Catt S, Cui Y, Hennighausen L, Gonzalez F, Rohrer J, Benninghoff AU \& Hontecillas R (2004) Activation of PPAR $\gamma$ and $\delta$ by conjugated linoleic acid mediates protection from experimental inflammatory bowel disease. Gastroenterology 127, 777-791. 
34. Whelan J, Surette ME, Hardardottir I, Lu G, Golemboski KA, Larsen E \& Kinsella JE (1993) Dietary arachidonate enhances tissue arachidonate levels and eicosanoid production in Syrian hamsters. J Nutr 123, 2174-2185.

35. Mohrhauer H \& Holman RT (1963) The effect of dose level of essential fatty acids upon fatty acid composition of the rat liver. $J$ Lipid Res 4, 151-159.

36. Danon A, Heimberg M \& Oates JA (1975) Enrichment of rat tissue lipids with fatty acids that are prostaglandin precursors. Biochim Biophys Acta 388, 318-330.

37. Leaf A \& Weber PC (1988) Cardiovascular effects of $n-3$ fatty acids. N Engl J Med 318, 549-557.

38. Kinsella JE, Lokesh B, Broughton S \& Whelan J (1990) Dietary polyunsaturated fatty acids and eicosanoids: potential effects on the modulation of inflammatory and immune cells: an overview. Nutrition 6, 24-44; discussion 59-62.

39. Kwon KH, Murakami A, Tanaka T \& Ohigashi H (2005) Dietary rutin, but not its aglycone quercetin, ameliorates dextran sulfate sodium-induced experimental colitis in mice: attenuation of pro-inflammatory gene expression. Biochem Pharmacol 69, $395-406$.

40. Anonymous (2004) Suppressive activity of a fermented grain food product on dextran sulfate sodium-induced experimental colitis in mice. Biofactors 21, 179-184.
41. Liu C, Russell RM, Smith DE, Bronson RT, Milbury PE, Furukawa S, Wang XD \& Blumberg JB (2004) The effect of dietary glutathione and coenzyme Q10 on the prevention and treatment of inflammatory bowel disease in mice. Int J Vitam Nutr Res $\mathbf{7 4 ,}$ $74-85$.

42. Micallef MJ, Iwaki K, Ishihara T, Ushio S, Aga M, Kunikata T, Koya-Mitaya S, Kimoto T, Ikeda M \& Kurimoto M (2002) The natural plant product tryptanthrin ameliorates dextran sodium sulfate-induced colitis in mice. Int Immunopharmacol $\mathbf{2}$, $565-578$.

43. Lawson LD \& Hughes BG (1988) Human absorption of fish oil fatty acids as triacylglycerols, free acids, or ethyl esters. Biochem Biophys Res Commun 152, 328-335.

44. Anonymous (1988) Absorption of eicosapentaenoic acid and docosahexaenoic acid from fish oil triacylglycerols or fish oil ethyl esters co-ingested with a high-fat meal. Biochem Biophys Res Commun 156, 960-963.

45. el Boustani S, Colette C, Monnier L, Descomps B, Crastes de Paulet A \& Mendy F (1987) Enteral absorption in man of eicosapentaenoic acid in different chemical forms. Lipids 22, $711-714$.

46. Anonymous (1999) Dietary supplementation with $n-3$ polyunsaturated fatty acids and vitamin $\mathrm{E}$ after myocardial infarction: results of the GISSI-Prevenzione trial. Lancet 354, 447-455. 